\title{
Early Cure Behavior of a Liquid Dicyanate Ester Resin
}

\author{
KING-FU LIN, JING-YAU SHYU \\ Institute of Materials Science and Engineering, National Taiwan University, Taipei, Taiwan 10617 (Republic of China)
}

Received 8 March 2001; accepted 30 June 2001

\begin{abstract}
The early cure behavior of 4,4-dicyanato 1,1-diphenolethane resin with and without incorporating $\mathrm{Cr}(\mathrm{acac})_{3}, \mathrm{Co}(\mathrm{acac})_{3}$, and $\mathrm{Cu}(\mathrm{acac})_{2}$, respectively, as catalysts was investigated by gel permeation chromatography. The curing intermediates were separated by the column elution method and characterized by Fourier transform infrared, ${ }^{1} \mathrm{H}$, and ${ }^{3} \mathrm{C}$ NMR spectroscopies. The results indicated that the formed dimer in the early cure stage is a straight chain containing a primary amino group. The formed triazine ring in the trimer has a strong catalytic effect on the remaining cyanate groups so that the reactivity of the trimers was significantly increased. The reactivities of the curing intermediates decreased with molecular size until 7-mer was reached. The initial monomer consumption is described by second-order-rate kinetics. In the presence of metal acetylacetonates, the curing reactions may be accelerated, but they did not change the reaction path and preceding sequence of reactivities. () 2001 John Wiley \& Sons, Inc. J Polym Sci Part A: Polym Chem 39: 3085-3092, 2001
\end{abstract}

Keywords: cyanate esters; thermosets; curing of polymers; triazine ring; gel permeation chromatography (GPC)

\section{INTRODUCTION}

Cyanate ester resins are thermosetting materials, featured with a low dielectric constant, high glass-transition temperature, and good mechanical and processing properties. It has generally been agreed that cyclotrimerization reactions of cyanate groups that form a highly crosslinked polytriazine network are dominant curing reactions. ${ }^{1-5}$ The initiation of the reactions requires the presence of a small amount of aryl phenol impurities or adventitious water. ${ }^{6}$ The reactions can also be catalyzed by transition-metal complexes. However, there are discrepancies in the literature about the formation of dimeric species prior to triazine ring formation. ${ }^{7-11}$

Fyfe et al. $^{7}$ suggested that, based on their study on the mechanism of the curing reactions of

Correspondence to: K.-F. Lin (E-mail: kflin@ccms.ntu. edu.tw)

Journal of Polymer Science: Part A: Polymer Chemistry, Vol. 39, 3085-3092 (2001) (C) 2001 John Wiley \& Sons, Inc. bisphenol A dicyanate resin, no NMR evidence for the formation of dimeric or other intermediate species was observed prior to the formation of the triazine ring. However, Grenier-Loustalot and colleagues $^{9,10}$ detected a dimeric species during the cure of cumyl phenyl cyanate, a monofunctional resin, via high-performance liquid chromatography and liquid-state ${ }^{13} \mathrm{C}$ NMR. They suggested the formation of cyclic structures in the dimers. Gupta and Macosko ${ }^{11}$ have also detected dimers during the cure of bisphenol A dicyanate resin with gel permeation chromatography (GPC). However, they disagreed with GrenierLoustalot and colleagues ${ }^{9,10}$ over the formation of cyclic structures in the dimers because the twomembered rings with band angles of $90^{\circ}$ are highly strained and improbable to form. Gupta and Macosko ${ }^{11}$ suggest that the structure of the dimer is most likely a straight chain, although no further evidence was provided.

In this study, we used GPC to investigate the early cure behavior of 4,4-dicyanato 1,1-diphenolethane (DCDPE), a liquid dicyanate resin, with 

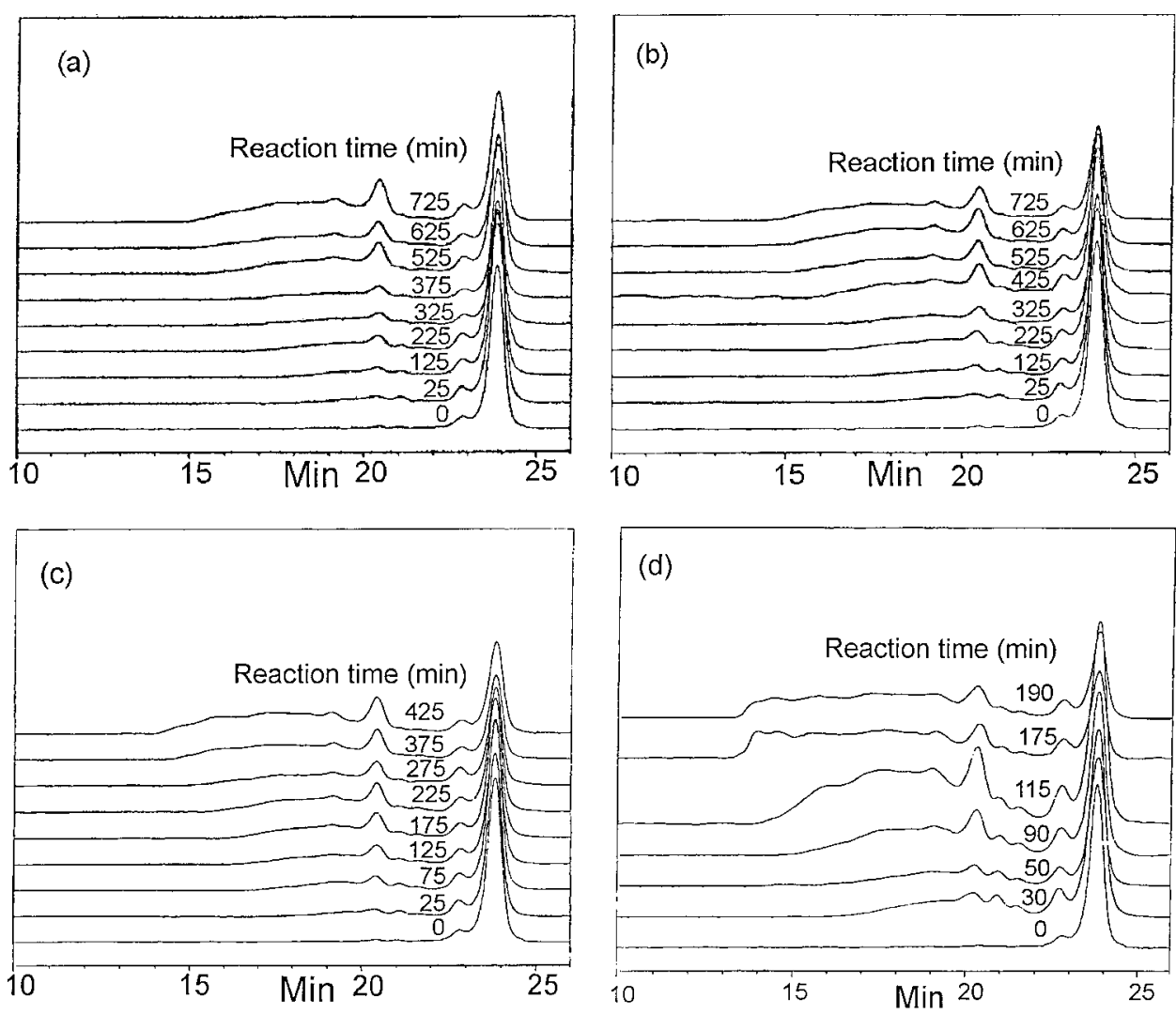

Figure 1. GPC spectra of (a) DCDPE resin and those incorporating $0.05 \mathrm{phr}$ of (b) $\mathrm{Cr}(\mathrm{acac})_{3}$, (c) $\mathrm{Co}(\mathrm{acac})_{3}$, and (d) $\mathrm{Cu}(\text { acac })_{2}$, respectively, after curing at $110{ }^{\circ} \mathrm{C}$ for various indicated times.

and without metal acetylacetonates as catalysts. The dimers were separated by the column elution method and characterized by Fourier transform infrared (FTIR), ${ }^{1} \mathrm{H}$, and ${ }^{3} \mathrm{C}$ NMR spectroscopies. The results indicate that the formed dimer is a stable straight chain containing a primary amino group, whereas the trimer is unstable and more reactive. The reactivities of the curing intermediates then decreased with molecular size until 7-mer was reached. In the presence of a catalyst, the curing reactions were accelerated, but they did not change the reaction path and preceding sequence of reactivities. Second-order-rate kinetics was also provided to describe the mechanism of initial monomer consumption.

\section{EXPERIMENTAL}

\section{Materials}

DCDPE (Ciba Geigy L10) was used as received and mixed with $0.05 \mathrm{phr}$ of chromium acetylac- etonate $\left[\mathrm{Cr}(\mathrm{acac})_{3}\right.$, Hayashi Japan], cobalt acetylacetonate $\left[\mathrm{Co}(\mathrm{acac})_{3}\right.$, Nakarai Japan], and copper acetylacetonate $\left[\mathrm{Cu}(\mathrm{acac})_{2}\right.$, Aldrich], respectively, at room temperature by stirring until the latter was completely dissolved. Then, about 200 mg of DCDPE samples with and without metal acetylacetonates were loaded into glass vials individually and sealed. As such, several vials were prepared for each resin formulation. The weight of the resins was accurately measured to $0.01 \mathrm{mg}$. The glass vials with the samples were then immediately heated to $110{ }^{\circ} \mathrm{C}$ in an oven and maintained at that temperature. At a designated time interval (see Fig. 1), one vial for each resin formulation was withdrawn from the oven and immediately loaded with a premeasured volume of ice-cooled tetrahydrofuran (THF) solvent to prepare $0.02 \mathrm{~g} / \mathrm{mL}$ solution for the test. For separation of the reaction intermediates, the prepared solutions were vacuum-dried at room temperature, and then the dried products were redissolved in dichloromethane before passing through 


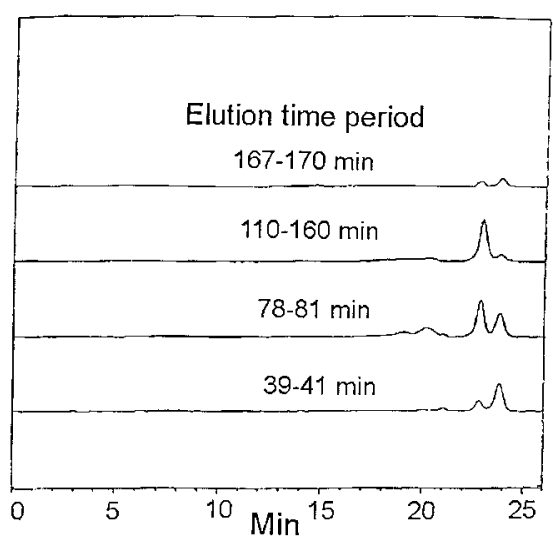

Figure 2. GPC spectra of the effluents flown out from the separation column in the indicated elution time periods for separation of the reaction intermediates of DCDPE resin incorporating $0.05 \mathrm{phr} \mathrm{Cr}(\mathrm{acac})_{3}$ after curing at $110{ }^{\circ} \mathrm{C}$ for $25 \mathrm{~min}$.

the separation column packed with silica gel (Merck Silica Gel 60). The effluents were repeatedly collected from the column for $3 \mathrm{~h}$. After draining all the solution in the separation column, the residue remaining in the column was flushed off with THF solvent and collected.

\section{Characterization}

GPC measurements with THF as the eluent (1 $\mathrm{mL} / \mathrm{min}$ ) were carried out at $40{ }^{\circ} \mathrm{C}$ using a Testhigh series III pump and a Testhigh refractiveindex detector. One PhenolGEL 550A and two PhenolGEL MXL columns in series were used for separation of the reaction intermediates. Their molecular weight was estimated by referring to the polystyrene standards with a narrow molecular weight distribution. FTIR spectra were recorded on a Jasco 300E FTIR spectrometer with the specimens coated on a $\mathrm{KBr}$ plate. ${ }^{1} \mathrm{H}$ and ${ }^{13} \mathrm{C}$ NMR spectroscopies of the reaction intermediates were carried out with a Bruker Model AM-500WB NMR spectrometer. The samples were vacuumdried at room temperature first and then redissolved in deuterated chloroform.

\section{RESULTS AND DISCUSSION}

\section{Reaction Intermediates}

Figure 1 shows the GPC spectra of DCDPE resins with and without $0.05 \mathrm{phr}$ of $\mathrm{Cr}(\mathrm{acac})_{3}, \mathrm{Co}(\mathrm{acac})_{3}$, and $\mathrm{Cu}(\mathrm{acac})_{2}$, respectively, after reacting at 110
${ }^{\circ} \mathrm{C}$ at various times. The neat resin contained a small amount of dimers and multimers. When the reactions proceeded at $110{ }^{\circ} \mathrm{C}$ for $25 \mathrm{~min}$, the amount of dimers and multimers increased for all four samples. The neat resin and that incorporating $\mathrm{Cr}(\mathrm{acac})_{3}$ have a similar reactivity. They both gelled after curing for $750 \mathrm{~min}$. The resin incorporating $\mathrm{Co}(\mathrm{acac})_{3}$ gelled after $425 \mathrm{~min}$, and that incorporating $\mathrm{Cu}(\mathrm{acac})_{2}$ gelled after $115 \mathrm{~min}$. Although the catalytic effect of metal acetylacetonates increases in the sequence of $\mathrm{Cu}(\mathrm{acac})_{2}$ $>\mathrm{Co}(\mathrm{acac})_{3}>\mathrm{Cr}(\mathrm{acac})_{3}$, the GPC spectra of all the resins under the same extent of cure are basically similar.

When the DCDPE resins incorporating 0.05 phr of $\mathrm{Cr}(\mathrm{acac})_{3}$ were reacted for $25 \mathrm{~min}$, their dimers were separated from the cured resins by the column elution method in an elution time period of 110-160 min, as shown in Figure 2. In fact, the dimers were eluted along with a small amount of monomers and barely detectable multimers. Their FTIR spectrum as compared with that of the DCDPE monomer (see Fig. 3) revealed that the effluent contained free primary amine groups (absorption peaks at 3500 and $3350 \mathrm{~cm}^{-1}$ contributed by stretching of $-\mathrm{NH}_{2}$ and at 1373 $\mathrm{cm}^{-1}$ by $\mathrm{C}-\mathrm{N}$ stretching ${ }^{12}$ ) and carbonyl groups (at $1720 \mathrm{~cm}^{-1}$ ). The ${ }^{1} \mathrm{H}$ NMR spectrum shown in Figure 4 indicates that the effluent had two kinds of free primary amine groups. The major resonance peak at $5.18 \mathrm{ppm}$ was contributed by the dimers whose chemical structure is outlined in Structure 1. On the other hand, the minor peak at $6.72 \mathrm{ppm}$ was mainly contributed by the carbamate groups formed by the reaction of monomers with adventitious water, whose structure is demonstrated in Structure 2.

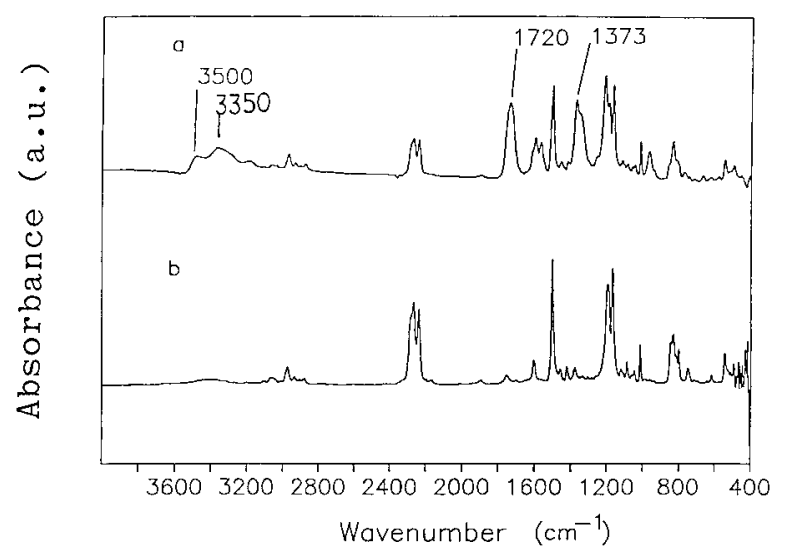

Figure 3. FTIR spectra of (a) the effluent in an elution time period of 110-160 min as indicated in Figure 2 and (b) DCDPE monomer. 

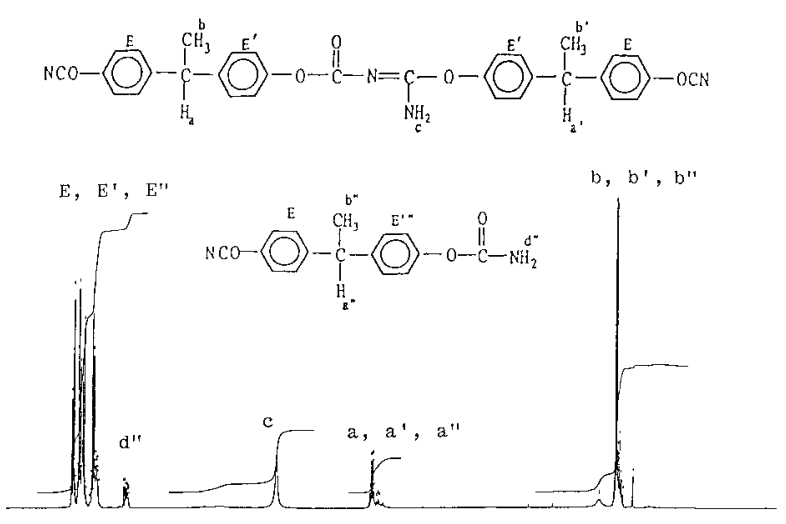

$\begin{array}{llllllll}\text { ppm } & 7 & 6 & 5 & 4 & 3 & 2 & 1\end{array}$

Figure 4. ${ }^{1} \mathrm{H}$ NMR spectrum of the effluent in an elution time period of $110-160 \mathrm{~min}$ as indicated in Figure 2.

The splitting of the minor peak resulted from the presence of aromatic protons close to the phenol groups of unconverted monomers. We have checked this small contribution from the ${ }^{1} \mathrm{H}-{ }^{13} \mathrm{C}$ chemical shift correlated two-dimensional NMR spectrum (data not shown). Grenier-Loustalot et al. ${ }^{9}$ also reported that the aromatic protons close to the phenol groups of unconverted bisphenol A diacyanate monomers have a chemical shift of 6.6 $\mathrm{ppm}$. The chemical structure of the previously shown dimers was further supported by ${ }^{13} \mathrm{C}$ NMR spectroscopy (see Fig. 5). It is probable that the dimers were formed by the reaction of a carbamate group of the preceding compound with an isocyanate group of the monomer. They are rather stable after formation and can stay with the DCDPE monomers at room temperature without proceeding with further detectable reactions for at least 1 week.

\section{Reactivity of Reaction Intermediates before Gelation}

Only part of the reaction intermediates of the DCDPE resins was flown out from the separation column after applying the column elution method

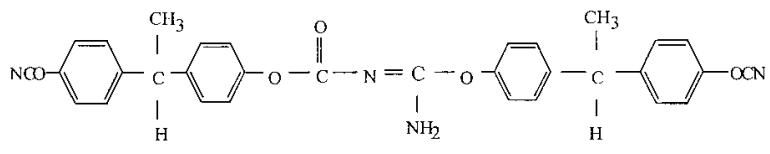

Structure 1

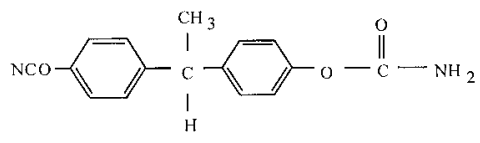

Structure 2

with dichloromethane as the mobile phase. After 200 min of elution, almost no reaction intermediate was detected in the effluent from the separation column. After that, the residue remaining in the column was flushed off with THF solvent, and its GPC spectrum exhibited a clear trimer peak at an elution time of $22.2 \mathrm{~min}$, as shown in Figure 6, that was not observed in the previous GPC spectra of the resin and its effluents. Apparently, trimer is less soluble in dichloromethane than in THF. By comparing the sequence of peaks appearing at different elution times among the GPC spectra of resin, its effluent, and the residue remaining in the separation column, we were able to identify peaks from monomer to 7-mer (see Fig. 6). Assuming that the area of the monomer peak of resin before curing is 1 , the number percentage of monomers to 7-mers at various curing times can estimated from Figure 1, and the results of the DCDPE resins containing $0.05 \mathrm{phr}$ of $\mathrm{Cr}(\mathrm{a}-$ cac) $)_{3}, \mathrm{Co}(\text { acac })_{3}$, and $\mathrm{Cu}(\mathrm{acac})_{2}$, respectively, are illustrated in Figure 7. As seen in the figure, the amount of monomers was gradually decreased with time for all three samples. Because of the similarity between the data of the neat resin and that containing $\mathrm{Cr}(\mathrm{acac})_{3}$, the former is not shown. The dimers, having produced about 7\% during resin storage, slightly increased and then barely decreased its number percentage before gelling for most of the samples except that con-
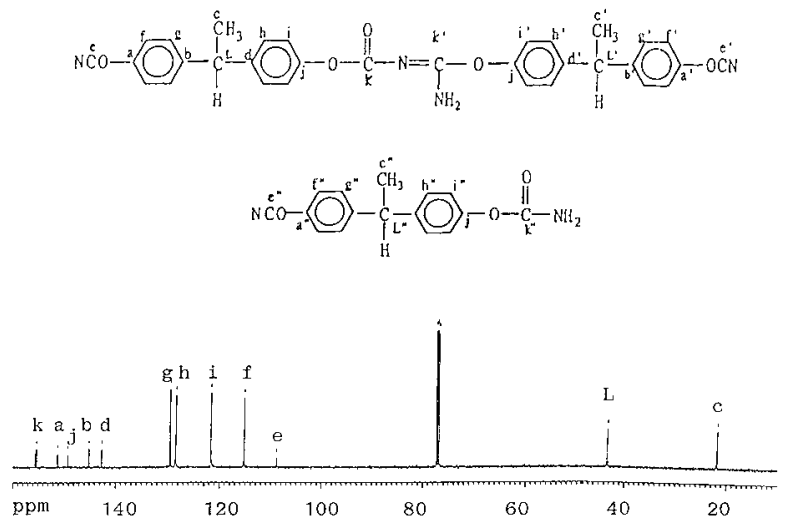

Figure 5. ${ }^{13} \mathrm{C}$ NMR spectrum of the effluent in an elution time period of $110-160 \mathrm{~min}$ as indicated in Figure 2. 


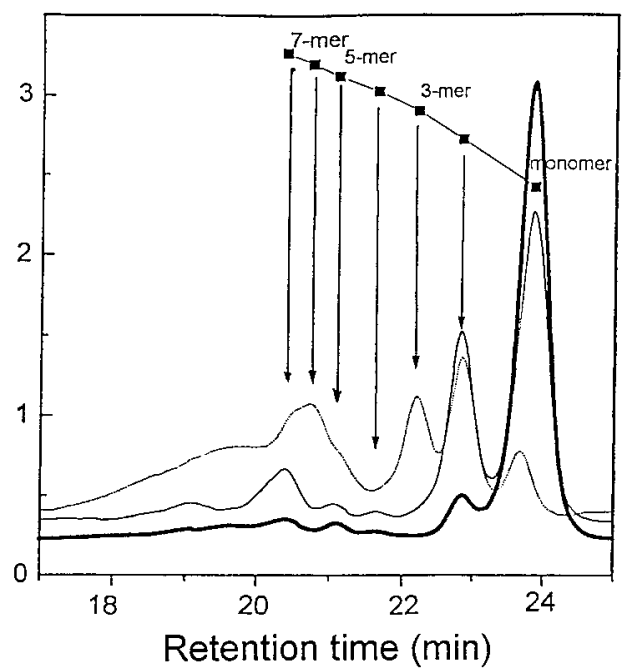

Figure 6. GPC spectra of (-) DCDPE resin incorporating $0.05 \mathrm{phr} \mathrm{Cr}(\mathrm{acac})_{3}$ after curing at $110{ }^{\circ} \mathrm{C}$ for 25 min, (-) its effluent from separation column in an elution time period of 50-53 $\mathrm{min}$, and $(\cdots)$ the residue that was unable to be removed from the separation column with dichloromethane, flushed off with THF.

taining $\mathrm{Cu}(\mathrm{acac})_{2}$. The detectable decrease of dimers for the latter was due to the higher extent of reaction caused by the greater catalytic effect of $\mathrm{Cu}(\mathrm{acac})_{2}$. The change in number percentage of the trimer, tetramer, and 5-mer almost followed the trend of the dimers. However, 6-mer and 7-mer slightly increased their amount. Nevertheless, the amount of the formed trimers for all four resin systems was the least compared with other multimers. In other words, their reactivity was the highest. As soon as the trimers were produced, they reacted to form tetramers. If the reactivity of the tetramer is higher than the trimer, then its amount would be lower than that of the latter. Additionally, the reactivity of 5-mers was lower than that of the tetramer. The reactivity decreased with molecular size until 7-mer was reached. Thus, the amount of multimers detected by GPC reflects their reactivities. Catalytic effects of $\mathrm{Cu}(\mathrm{acac})_{2}$ and $\mathrm{Co}(\mathrm{acac})_{3}$ on DCDPE resin only accelerated their reactions and did not change the preceding sequence of reactivities.

The cyclotrimerization reactions of cyanate groups that form triazine groups were dominant reactions in the initial cure of DCDPE resins as indicated by the ${ }^{13} \mathrm{C}$ NMR spectra in Figure 8 . The appearance of the resonance peak at $173 \mathrm{ppm}$ contributed by the carbons in triazine rings ${ }^{7}$ justified that the trimers and other multimers were a polytriazine. The highest reactivity of trimers as compared with other multimers indicates that the formed triazine ring has a strong catalytic effect on the remaining isocyanate groups. This catalytic effect has long been considered as the catalytic effect of triazine products on the overall curing reaction of cyanate resins. ${ }^{4} \mathrm{We}$ also believe this effect rendered the gel conversion at the gel point deviated from the theoretical prediction of $0.5^{11,13}$ because the formed triazine rings, which accelerate the reactions of neighbor cyanate groups, might facilitate the formation of intramolecular cycles.

According to the aforementioned experimental results, the initial cure path of DCDPE resins can be described by the following eqs.
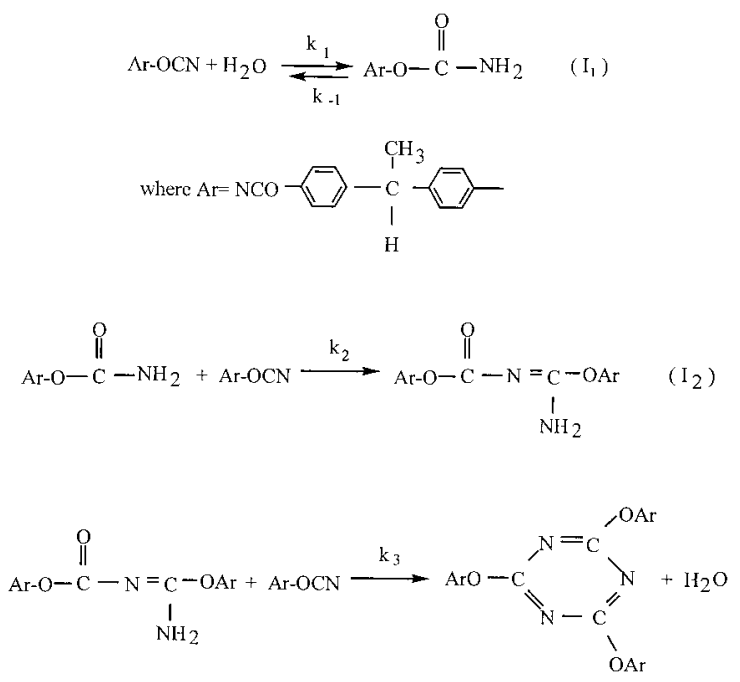

(T)
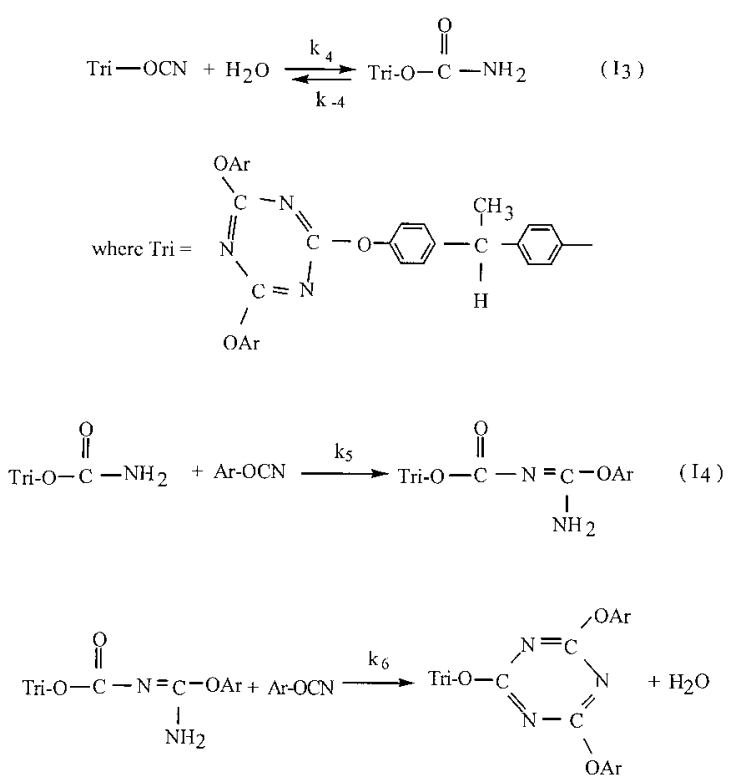

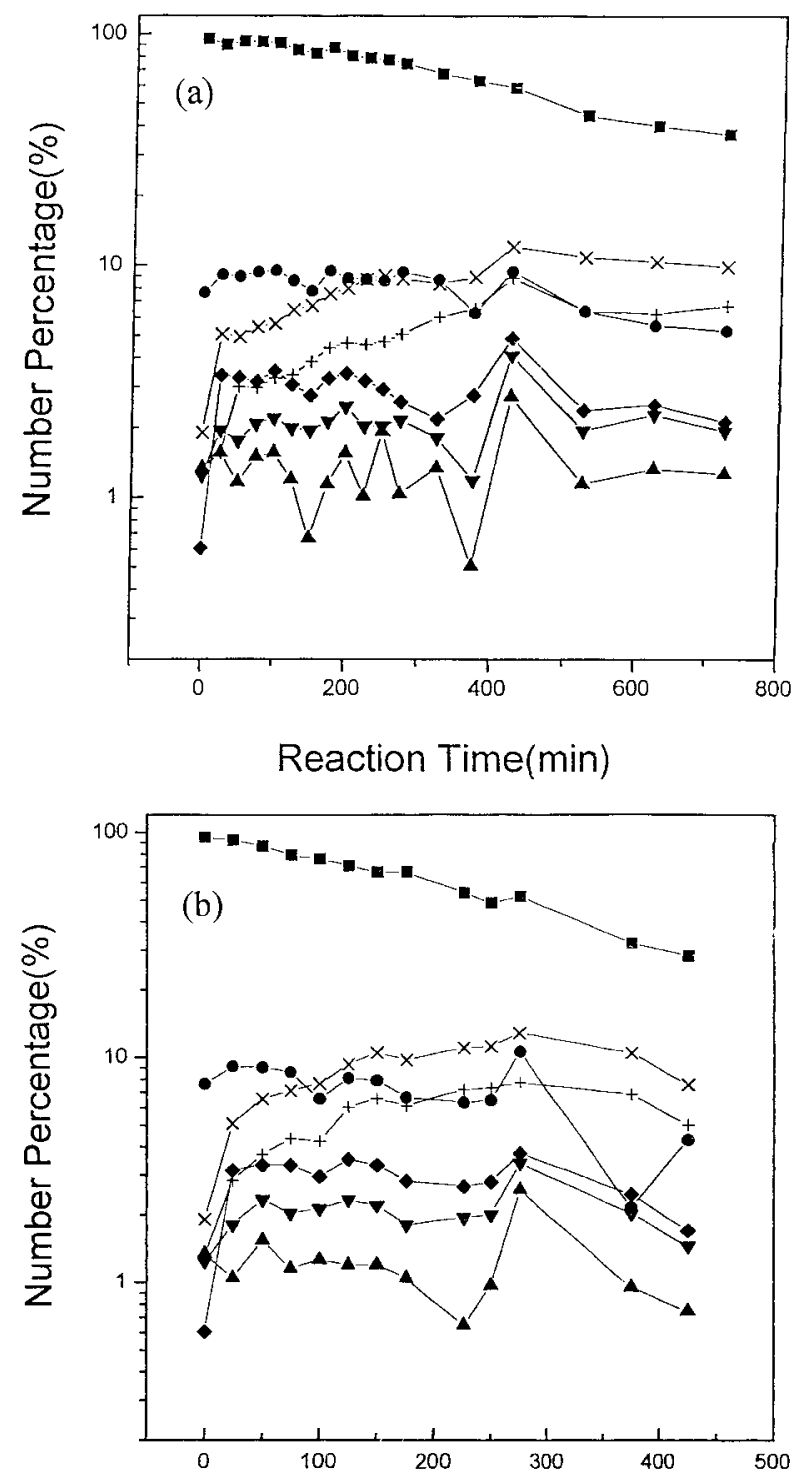

Reaction Time(min)

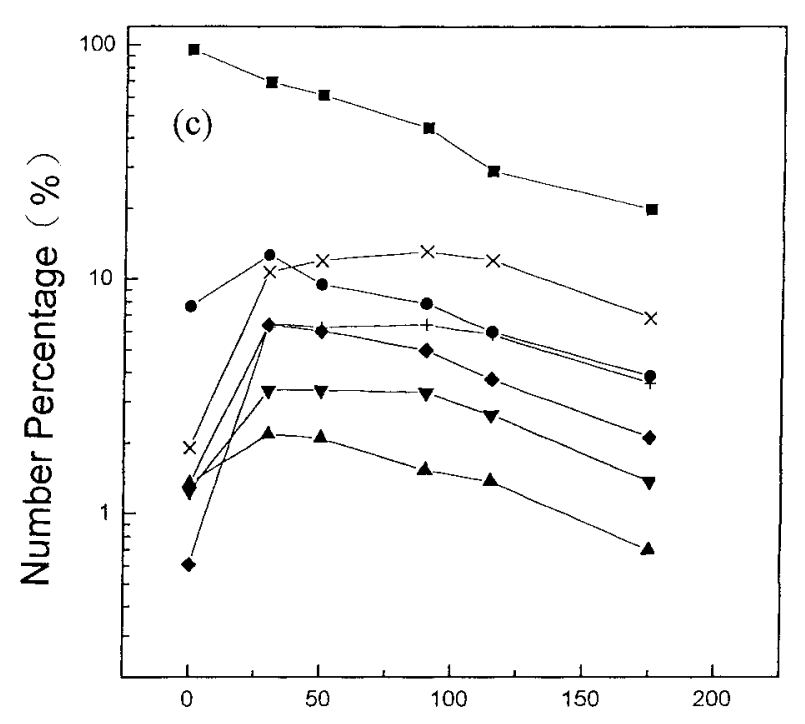

Reaction Time(min)

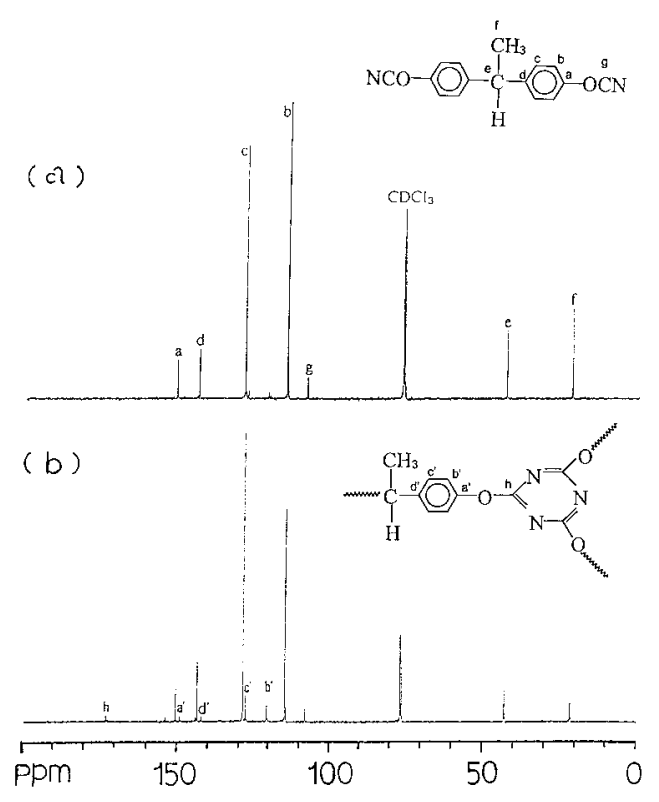

Figure 8. ${ }^{13} \mathrm{C}$ NMR spectra of (a) DCDPE monomers and (b) DCDPE resin after curing at $110{ }^{\circ} \mathrm{C}$ for $125 \mathrm{~min}$.

By following the suggested method, ${ }^{4}$ the equilibrium constant $K_{1}$ for reaction 1 is defined as

$$
K_{1}=\frac{k_{1}}{k_{-1}}=\frac{I_{1}}{C W}
$$

where $I_{1}, C$, and $W$ are the concentrations of imidocarbonate, monomers, and water, respectively. Because the concentrations of dimers, trimers, tetramers, and so forth were almost constant in the initial curing stage (see Fig. 7), the following quasi-steady-state conditions were assumed:

$$
\begin{aligned}
& \frac{d I_{2}}{d t}=k_{2} I_{1} C-k_{3} I_{2} C=0 \\
& \frac{d T}{d t}=k_{3} I_{2} C-k_{4} T W=0 \\
& \frac{d I_{3}}{d t}=k_{4} T W-k_{5} I_{3} C=0
\end{aligned}
$$

Figure 7. Plot of number percentage of ( $\square$ ) monomers, $(\bullet)$ dimers, ( $\mathbf{\Delta})$ trimers, $(\boldsymbol{\nabla})$ tetramers, $(\bullet)$ 5-mers, (+) 6-mers, and $(\times)$ 7-mers versus curing time at $110{ }^{\circ} \mathrm{C}$ for DCDPE resins containing $0.05 \mathrm{phr}$ of (a) $\mathrm{Cr}(\mathrm{acac})_{3}$, (b) $\mathrm{Co}(\mathrm{acac})_{3}$, and (c) $\mathrm{Cu}(\mathrm{acac})_{2}$. 


$$
\begin{gathered}
\frac{d I_{4}}{d t}=k_{5} I_{3} C-k_{6} I_{4} C=0 \\
\frac{d I_{n}}{d t}=k_{3 n-1 / 2} I_{n-1} C-k_{3 n+1 / 2} I_{n} C=0
\end{gathered}
$$

where $I_{n}$ is the concentration of n-mers, and $k_{3 n-1 / 2}$ and $k_{3 n+1 / 2}$ are the reaction constants at reaction steps of whole numbers of $3 n-1 / 2$ and $3 n+1 / 2$, respectively. Thus, the rate of monomer consumption, $d C / d t$, can be estimated by

$$
\begin{gathered}
-\frac{d C}{d t}=k_{2} I_{1} C+k_{3} I_{2} C+k_{5} I_{3} C+k_{6} I_{4} C+\cdots \\
+k_{3 n+1 / 2} I_{n} C \\
=n K_{1} k_{2} W C^{2}
\end{gathered}
$$

From the mass balance, the initial concentration of water, $W_{0}$, is expressed as follows

$$
\begin{gathered}
W_{o}=W+I_{1}+I_{2}+\cdots+I_{n} \\
=W\left(1+K_{1} C+\frac{k_{2}}{k_{3}} K_{1} C+\cdots+\frac{k_{2}}{k_{3 n+1 / 2} K_{1} C}\right) \\
=W(1+p)
\end{gathered}
$$

where

$$
p=K_{1} C+\frac{k_{2}}{k_{3}} K_{1} C+\cdots+\frac{k_{2}}{k_{3 n+1 / 2}} K_{1} C
$$

Assuming that $p \ll 1, W \approx W_{\mathrm{o}}$. Thus

$$
-\frac{d C}{d t}=k C^{2}
$$

where $k=n K_{1} k_{2} W_{o}$. By integrating eq 3, we obtain

$$
\frac{C_{o}}{C}-1=k C_{o} t
$$

where $C_{\mathrm{o}}$ is the initial concentration of monomer. Incorporating the experimental data of Figures 1 and 4 , we plotted $C_{\mathrm{o}} / C-1$ versus $t$ for all resin systems, as shown in Figure 9, and found that the data are well fit with eq 14 in the initial cure

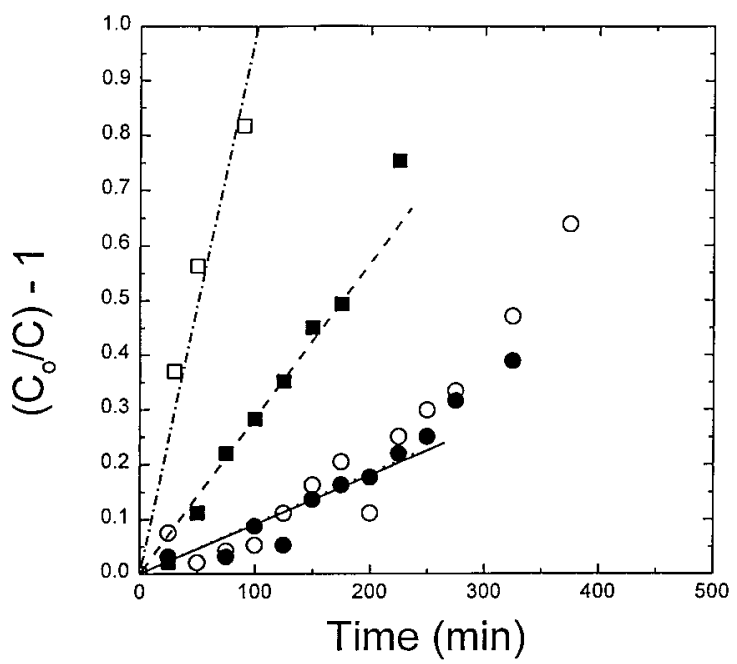

Figure 9. Plot of $\left(C_{\mathrm{o}} / C\right)-1$ versus curing time at 110 ${ }^{\circ} \mathrm{C}$ for $(\mathbf{O},-)$ DCDPE resin and those containing 0.05 phr of $(\bigcirc, \cdots \cdot) \operatorname{Cr}(\text { acac })_{3},(\square,-) \operatorname{Co}(\text { acac })_{3}$, and $(\square,-\cdot-)$ $\mathrm{Cu}(\mathrm{acac})_{2}$. The lines on the data were obtained by fitting the data with the first-order least-squares method.

stage but deviated after curing for $250 \mathrm{~min}$. Using the first-order least-squares method to fit the data before $250 \mathrm{~min}$, we can obtain the slope, $k C_{\mathrm{o}}$. $C_{\text {o }}$ was $4.29 \mathrm{M}(\mathrm{mol} / \mathrm{L})$, estimated from the density of DCDPE resin at $110{ }^{\circ} \mathrm{C}$. Thus, the rate constants, $k$, for monomer consumption of neat resin and those containing $\mathrm{Cr}(\mathrm{acac})_{3}, \mathrm{Co}(\mathrm{acac})_{3}$, and $\mathrm{Cu}(\mathrm{acac})_{2}$ were estimated as $2.10 \times 10^{-4}, 2.14$ $\times 10^{-4}, 6.62 \times 10^{-4}$, and $2.29 \times 10^{-3} \mathrm{M}^{-1} \mathrm{~min}^{-1}$, respectively. Most of the experimental data for monomer consumption after 200 min of curing were more than those predicted by second-orderrate kinetics, possibly because the latter did not consider the reactions between two individual growing chains, which become significant when the cure reaches the gel point.

\section{CONCLUSIONS}

This study has clearly identified the curing intermediates of DCDPE cyanate resins from dimer to 7-mer. The dimer is a stable species, but the trimer is the most reactive. The reactivity decreased with molecular size until 7-mer was reached. Although metal acetylacetonates can catalyze the curing reaction, they do not change the preceding sequence of reactivities. The monomer consumption in the initial cure stage can be described by second-order-rate kinetics. 
The authors acknowledge the financial support of the National Science Council in Taiwan, Republic of China, through Grant NSC 86-2216-E002-011.

\section{REFERENCES AND NOTES}

1. Gupta, A. M. Macromolecules 1991, 24, 3459-3491.

2. Owusu, O. A.; Martin, G. S.; Gotro, J. T. Polymer 1996, 37, 4869-4872.

3. Itoya, K.; Kakimoto, M.; Imai, Y. Polymer 1994, 35, 1203-1209.

4. Simon, S. L.; Gillham, J. K. J Appl Polym Sci 1993, 47, 461-485.

5. Liu, H.; George, G. A.; Halley, P. J. Polymer 1997, 38, 2997-3002.

6. Bauer, M.; Bauer, J. In Chemistry and Technology of Cyanate Ester Resins; Hamerton, I., Ed.;
Chapman \& Hall: London, 1994; Chapter 3, pp 58-86.

7. Fyfe, C. A.; Niu, J.; Rettig, S. J.; Burlinson, N. E.; Reidsema, C. M.; Wang, D. W.; Poliks, M. Macromolecules 1992, 25, 6289-6301.

8. Fyfe, C. A.; Niu, J.; Rettig, S. J.; Wang, D. W.; Poliks, M. D. J Polym Sci Part A: Polym Chem 1994, 32, 2203-2221.

9. Grenier-Loustalot, M. F.; Lartigau, C.; Grenier, P. Eur Polym J 1995, 31, 1139-1153.

10. Grenier-Loustalot, M. F.; Lartigau, C. J Polym Sci Part A: Polym Chem 1997, 35, 1245-1254.

11. Gupta, A. M.; Macosko, C. W. Macromolecules 1993, 26, 2455-2463.

12. Nakanishi, K.; Solomon, P. H. Infrared Absorption Spectroscopy, 2nd ed.; Nankodo: Tokyo, 1977; pp $248-251$.

13. Lin, R. H.; Hong, J. L.; Su, A. C. Comput Theor Polym Sci 1997, 7, 95-100. 